\title{
Gross anatomical investigation of the posterolateral aspect of the forearm for ulnar nerve block in Black Bengal goat (Capra hircus)
}

\author{
Tuli Dey ${ }^{1}$, Sonnet Poddar ${ }^{2}$, Abdullah Al Faruq ${ }^{2}$, Jabin Sultana ${ }^{3}$, Salma Akter ${ }^{4}$ \\ ${ }^{1}$ Department of Medicine and Surgery, Chittagong Veterinary and Animal Sciences University, Khulshi, Chittagong, Bangladesh \\ ${ }^{2}$ Department of Anatomy and Histology, Chittagong Veterinary and Animal Sciences University, Khulshi, Chittagong, Bangladesh \\ ${ }^{3}$ Department of Physiology, Biochemistry and Pharmacology, Chittagong Veterinary and Animal Sciences University, Khulshi, Chittagong, Bangladesh \\ ${ }^{4}$ Department of Medicine, Surgery and Obstetrics, Hajee Mohammad Danesh Science and Technology University, Dinajpur, Bangladesh
}

\begin{abstract}
Objectives: The aim of this study was to investigate the gross anatomical features of the ulna and radius bones on the posterolateral aspect of the forearm in Black Bengal goat (Capra hircus) to determine the site for ulnar nerve block.

Methods: 15 radius and ulna bones of Black Bengal goats from three different age groups (Group A: 1-2 years; Group B: 2-3 years; Group C: $>3$ years) were studied. Measurements of the length between the olecranon tuberosity and styloid process on the posterolateral aspect of radius and ulna bones were made, and the mean midpoints on this line were determined.

Results: Ulna was always fused with the radius except on the posterolateral interosseous spaces at the proximal and distal ends. The ulnar nerve coursed posterior to the ulna, between the flexor carpi ulnaris and ulnaris lateralis muscles, and remained superficial at the midpoint of ulna. Mean lengths of the midpoint on the posterolateral aspect of the ulna (on the line between the olecranon tuberosity to the styloid process) were $7.27 \pm 0.16,7.67 \pm 0.34$ and $8.29 \pm 0.73 \mathrm{~cm}$ in Groups A, B and C, respectively.

Conclusion: These anatomical findings indicate that these mean midpoints are the most convenient sites for ulnar nerve block in these three age groups of Black Bengal goats.
\end{abstract}

Keywords: blocking site; forearm; gross anatomy; ulnar nerve; Black Bengal goat

Anatomy 2018;12(3):115-117 (2018 Turkish Society of Anatomy and Clinical Anatomy (TSACA)

\section{Introduction}

The forearm of Black Bengal goat (Capra hircus) consists of two large bones named radius and ulna. It extends in a vertical direction from elbow joint. ${ }^{[1,2]}$ Radius is much larger, but not longer than the ulna bone. The posterior surface of the radius bone is concave and fused with the cranial surface of the shaft of ulna bone except for the two interosseous spaces situated at the proximal and distal ends of the bone. ${ }^{[1,3]}$ Proximal part of the ulna bears the olecranon tuberosity and the trochlear notch. The caudal border of the ulna is straight, thick and rounded. Styloid process is a pointed projection of the distal end of ulna which faces the posterolateral aspect of the radius. The ulnar nerve courses along the posterior border of the ulna. ${ }^{[1,4]}$ Block of the ulnar nerve for surgical purposes can be performed at various levels along its course in the forearm region. There are very few studies performed for determination of the site of ulnar nerve block. ${ }^{[4,5]}$ Therefore, this study was planned to to determine the site for ulnar nerve block in Black Bengal goats with gross anatomical investigation of the posterolateral aspect of the forearm.

\section{Materials and Methods}

The study was conducted on the forearm of Black Bengal goats between March 2 and May 10, 2016. Fifteen forearms from different aged groups of Black Bengal goats were collected from the local market, Khulshi, Chittagong, Bangladesh. The bones were graved for 2 months, excavated out and processed as described by 
Gofur and Khan (2010) ${ }^{[6]}$ The radius and ulna bones of Black Bengal goats were divided into three groups according to their age. Group A: between 1-2 years Group B: between 2-3 years, and Group C: older than 3 years. Gross anatomical investigation of the posterolateral aspect of the forearm was performed at the Department of Anatomy and Histology, Chittagong Veterinary and Animal Sciences University (CVASU), Khulshi, Chittagong, Bangladesh.

Gross anatomical investigation of the radius and ulna bones from Groups A, B and C were made at their posterolateral aspects. Measurements of the length between the olecranon tuberosity and styloid process on the posterolateral aspect of radius and ulna bones were made, and the mean midpoints on this line were determined.
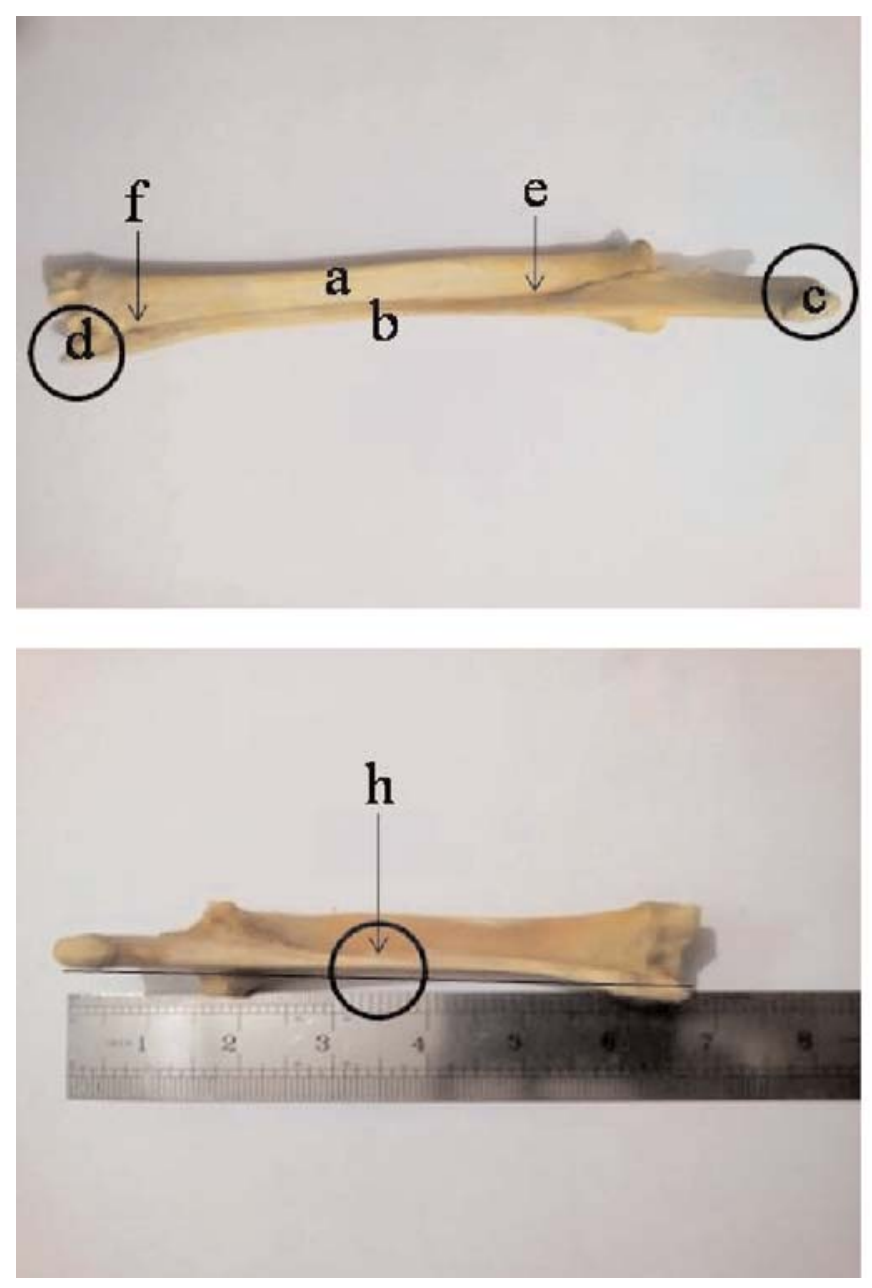

After this, the most suitable site for ulnar nerve block was determined.

\section{Results}

The body of thw radius bone was flattened craniocaudally. The ulna was longer and fused with radius along its posterolateral aspect, except at the proximal and distal interosseous spaces (Figure 1). Proximal end of the ulna was expanded with a rough prominence called the olecranon tuberosity. On the distal end, there was a pointed projection named the styloid process of the ulna. The mean midpoint on the line between the olecranon tuberosity and the styloid process were $7.27 \pm 0.16,7.67 \pm 0.34$ and $8.29 \pm 0.73 \mathrm{~cm}$ in Groups A, B and C, respectively (Table 1). At the forearm region, the ulnar nerve coursed poste-
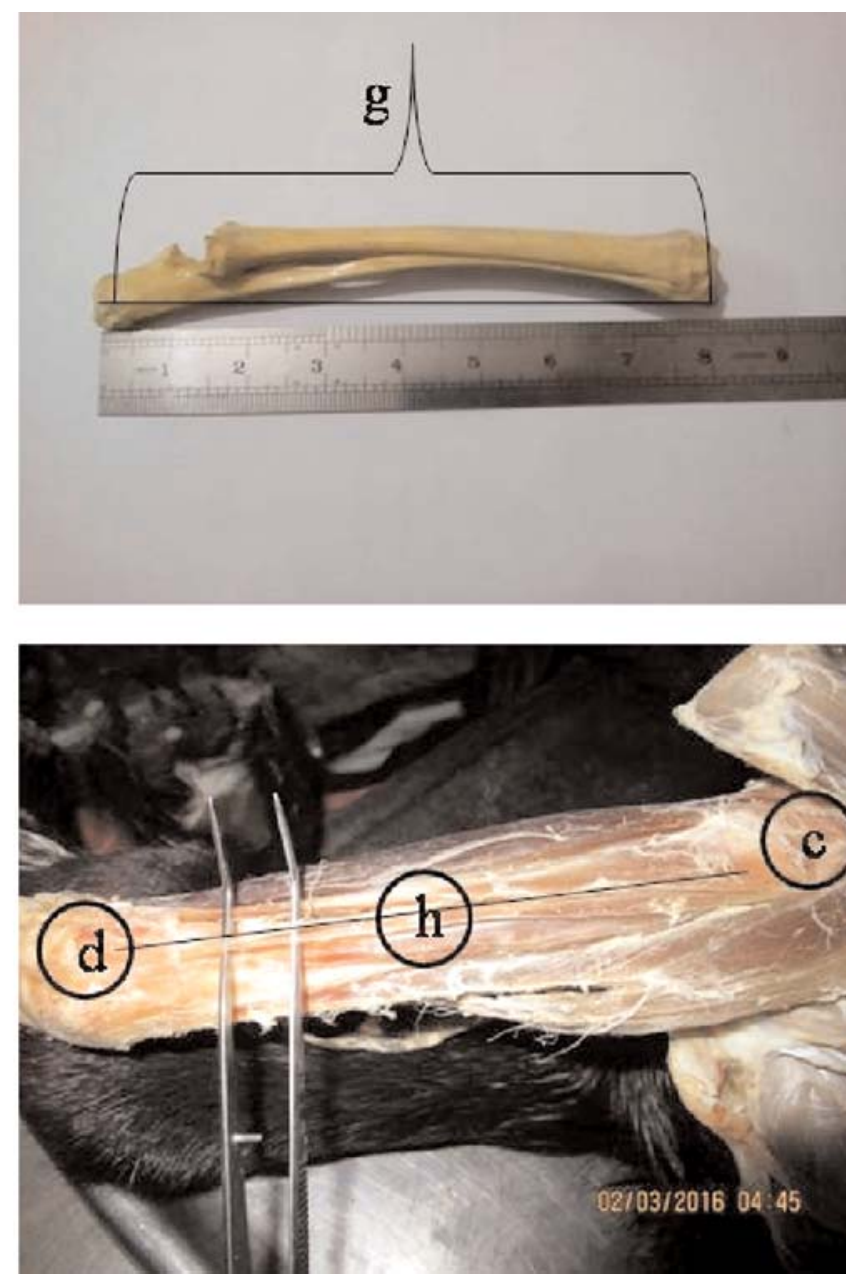

Figure 1. Radius and ulna bones, and the midpoint on the line between the olecranon tuberosity and the styloid process for ulnar nerve block. a: radius; b: ulna; c: olecranon tuberosity; d: styloid process; e: proximal interosseous space; f: distal interosseous space; g: total length along olecranon tuberosity to styloid process; h: midpoint on the line between the olecranon tuberosity and the styloid process. [Color figure can be viewed in the online issue, which is available at www.anatomy.org.tr] 
Table 1

Length between the olecranon tuberosity to styloid process of ulna (posterolateral aspect) in different aged groups of Black Bengal goats (Mean \pm SD)

\begin{tabular}{lccc}
\hline Age groups & Number of bones & Mean length between OT and SP & Mean midpoint distance (cm) \\
\hline Group A: 1-2 years & 5 & $14.53 \pm 0.16$ & $7.27 \pm 0.16$ \\
Group B: 2-3 years & 6 & $15.33 \pm 0.34$ & $7.67 \pm 0.34$ \\
Group C: >3 years & 4 & $16.58 \pm 0.73$ & $8.29 \pm 0.73$ \\
\hline
\end{tabular}

rior to the ulna and passed between the flexor carpi ulnaris and ulnaris lateralis muscles.

\section{Discussion}

In this study, we found that the ulna bone was fused with the radius along its posterolateral aspect except for the proximal and distal interosseous spaces, similar with the findings of Getty, ${ }^{[1]}$ Mahmud and Mussa, ${ }^{[7]}$ and Siddiqui et al. ${ }^{[8]}$ The olecranon tuberosity and styloid process of the ulna was observed in every bone, similar with the findings of Ghosh, ${ }^{[2]}$ Neil and May, ${ }^{[3]}$ and Siddiqui et al. ${ }^{[8]}$ The mean midpoint length along the olecranon tuberosity and styloid process were $7.27 \pm 0.16,7.67 \pm 0.34$ and $8.29 \pm 0.73 \mathrm{~cm}$ in Groups A, B and C age group Black Bengal goats, respectively. At the midpoint of the forearm, the ulnar nerve courses more superficially to pass between the flexor carpi ulnaris and ulnaris lateralis muscles. ${ }^{[1,4]}$ So, the midpoint of the the distance between the olecranon tuberosity and the styloid process of ulna on the posterolateral aspect was the most convenient site for ulnar nerve block Black Bengal goats (Figure 1).

\section{Conclusion}

Gross anatomical investigation of the radius and ulna revealed that the ulna is fused with radius on its posterolateral aspect. For surgical purposes, ulnar nerve block can be performed at various levels along its the course in the forearm region, but is more convent at the midpoint of the line between the olecranon tuberosity and the styloid process of the ulna on its posterolateral aspect.

\section{References}

1. Getty R. Session and Grossman's the anatomy of the domestic animals. 2nd ed. Vol. 1. Philadelphia (PA): W.B. Saunders; 1975.

2. Ghosh RK. Primary veterinary anatomy. 5th ed. Kolkata: Current Books International; 2012.

3. May NDS. Anatomy of the sheep. 2nd ed. Brisbane: University of Queenesland Press; 1964.

4. Skarda RT, Tranquilli WJ. Local anesthetics. In: Tranquilli WJ, Thurmon JC, Grimm KA, editors. Lumb and Jone' veterinary anesthesia and analgesia. 4th ed. Ames (IA): Blackwell Publishing; 2007. p. $395-418$.

5. Ghadirian S, Vesal N. Brachial plexus block using lidocaine/epinephrine or lidocaine/xylazine in fat-tailed sheep. Vet Res Forum 2013;4:161-7.

6. Gofur MR, Khan MSI. Development of a quick, economic and efficient method for preparation of skeleton of small animals and birds. International Journal of BioResearch 2010;2:13-7.

7. Mahmud AA, Mussa, T. Comparative macro anatomy of forelimb bones of Black Bengal Goat and indigenous dog: an overview. American Journal of Agricultural Science Engineering and Technology 2016;3:1-10.

8. Siddiqui MSI, Khan MZI, Sarma M, Moonmoon S, Islam MN, Jahan MR. Macro-anatomy of the bones of the limb of Black Bengal goat (Capra bircus). Bangladesh Journal of Veterinary Medicine 2008;6: 59-66.

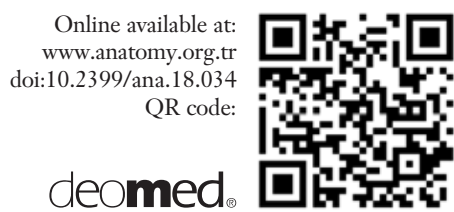

Correspondence to: Sonnet Poddar, DVM, MS

Department of Anatomy and Histology, Chittagong Veterinary and

Animal Sciences University, Khulshi, Chittagong, Bangladesh

Phone: +8801721429218

e-mail: sonnetcvasu@gmail.com

Conflict of interest statement: No conflicts declared.

This is an open access article distributed under the terms of the Creative Commons Attribution-NonCommercial-NoDerivs 3.0 Unported (CC BY-NCND3.0) Licence (http://creativecommons.org/licenses/by-nc-nd/3.0/) which permits unrestricted noncommercial use, distribution, and reproduction in any medium, provided the original work is properly cited. Please cite this article as: Dey T, Poddar S, Faruq AA, Sultana J, Akter S. Gross anatomical investigation of the posterolateral aspect of the forearm for ulnar nerve block in Black Bengal goat (Capra hircus). Anatomy 2018;12(3):115-117. 